\title{
Mengembangkan Koperasi Syariah di Indonesia: Pendekatan Interpretative Structural Modelling (ISM)
}

\author{
Aam Slamet Rusydiana \\ Shariah Economic Applied Research and Training (SMART) Indonesia \\ email: aamsmart@gmail.com
}

\author{
Abrista Devi \\ Universitas Ibnu Khaldun Bogor \\ email: abristasmart@gmail.com
}

\begin{abstract}
Despite growing rapidly, but Islamic cooperatives are still experiencing many obstacles in its development, both from the internal, external and regulatory side. This study attempts to identify the factors of needs, activities, and objectives in the development of sharia cooperatives in Indonesia, using the Interpretative Structural Modelling (ISM) approach. The results of this study provide some conclusions include: (1) Elements of the needs of the key key in sharia cooperative development strategy in Indonesia to improve SMEs is the need for strong support on the legal aspects of sharia cooperatives, (2) Elements of activities that are key to Shariah cooperative development are to conduct training and certification programs for shariah cooperative management and members, and (3) Elements of actors/institutions that are key in sharia cooperative development strategy in Indonesia to improve UMKM is sharia financial institution.
\end{abstract}

Keywords: Islamic Cooperatives; Islamic Microfinance Institutions; Interpretative Structural Modelling (ISM).

Abstrak: Walaupun tumbuh dengan pesat, namun koperasi syariah masih mengalami banyak kendala dalam pengembangannya, baik dari sisi internal, eksternal maupun regulasi. Penelitian ini mencoba untuk mengidentifikasi faktor-faktor kebutuhan, aktifitas dan tujuan dalam pengembangan koperasi syariah di Indonesia, dengan pendekatan metode Interpretative Structural Modelling (ISM). Hasil penelitian memberikan beberapa kesimpulan, antara lain: (1) Elemen kebutuhan yang menjadi kunci utama dalam strategi pengembangan koperasi syariah di Indonesia untuk meningkatkan UMKM adalah perlu adanya dukungan yang kuat pada aspek hukum koperasi syariah, (2) Elemen aktifitas yang menjadi kunci utama dalam pengembangan koperasi syariah adalah mengadakan training dan program sertifikasi bagi manajemen koperasi syariah dan anggota, dan (3) Elemen pelaku/lembaga yang menjadi kunci utama dalam strategi pengembangan koperasi syariah di Indonesia untuk meningkatkan UMKM adalah lembaga keuangan syariah.

Kata Kunci: Koperasi Syariah; Lembaga Keuangan Mikro Syariah (LKMS); Interpretative Structural Modelling (ISM).

Economica: Jurnal Ekonomi Islam - Volume 9, Nomor 1 (2018) 


\section{Pendahuluan}

Koperasi syariah merupakan kelompok swadaya masyarakat sebagai lembaga ekonomi rakyat yang berupaya mengembangkan usaha-usaha produktif dan investasi dengan berdasar prinsip syariah. Keberadaan koperasi syariah dengan jumlah yang signifikan pada beberapa daerah di Indonesia tidak didukung oleh faktor-faktor pendukung yang memungkinkan lembaga mikro ini untuk terus berkembang dan berjalan dengan baik. Fakta yang ada di lapangan menunjukkan banyak koperasi syariah yang tenggelam dan bubar.

Dengan melihat fenomena di atas, perkembangan koperasi syariah dipandang belum sepenuhnya mampu menjawab problem real ekonomi yang ada di kalangan masyarakat. Hal ini disebabkan oleh beberapa faktor antara lain, belum memadainya sumber daya manusia yang terdidik dan profesional, menyangkut manajemen sumber daya manusia dan pengembangan budaya serta jiwa wirausaha (entrepreneurship) bangsa kita yang masih lemah, permodalan (dana) yang relatif kecil dan terbatas, adanya ambivalensi antara konsep syariah pengelolaan LKMS dengan operasionalisasi di lapangan, tingkat kepercayaan yang masih rendah dari umat Islam dan secara akademik belum terumuskan dengan sempurna untuk mengembangkan lembaga keuangan syariah dengan cara sistematis dan proporsional. Kompleksitas persoalan tersebut menimbulkan dampak terhadap kepercayaan masyarakat tentang keberadaan koperasi syariah di antara lembaga keuangan konvensional.

Padahal bila dilihat dari latar belakang berdirinya, koperasi syariah merupakan jawaban terhadap tuntutan dan kebutuhan kalangan umat Muslim. Kehadiran koperasi syariah muncul di saat umat Islam mengharapkan adanya lembaga keuangan yeng berbasis syariah dan bebas dari unsur riba yang dinyatakan haram. Beberapa model pembiayaan lain yang ada adalah model berbasis tanggung renteng atau dikenal dengan istilah group lending model (Akanji 2007); (Lukman et al. 2008); (Schurmann and 
Johnston 2009), dan (Fukuyama 2002). Demikian pula bentuk koperasi kredit dengan basis bunga (Stiglitz 1990), (Banerjee, Besley, and Guinnane 1994), (Rudjito 2003), dan (Robinson 2001).

Jika melihat data, pertumbuhan koperasi syariah di Indonesia (termasuk di dalamnya BMT) terus meningkat dengan pesat, Menurut Suharto (Suharto 2010), perkembangan BMT tahun 2010 tumbuh rata-rata dari sisi aset dalam kisaran 35\% - 40\%, financing to deposit ratio (dana yang disalurkan) juga masih sekitar 100\%. Hal ini membuktikan bahwa koperasi syariah dapat diterima oleh masyarakat sebagai lembaga yang dapat memberdayakan masyarakat kecil.

Eksistensi lembaga keuangan mikro syariah jelas memiliki arti penting bagi pembangunan ekonomi berwawasan syariah terutama dalam memberikan solusi bagi pemberdayaan usaha kecil dan menengah serta menjadi inti kekuatan ekonomi yang berbasis kerakyatan dan sekaligus menjadi penyangga utama sistem perekonomian nasional. Hal ini menunjukkan peranan koperasi syariah sangat berarti bagi masyarakat karena ia merupakan suatu lembaga mikro syariah yang mampu memecahkan permasalahan fundamental yang dihadapi oleh pengusaha kecil dan menengah khususnya di bidang permodalan. Koperasi syariah tidak hanya berfungsi dalam penyaluran modal tetapi juga berfungsi untuk menangani kegiatan sosial demikian juga mendukung keuangan inklusif. Keuangan inklusif adalah suatu keadaan dimana semua orang memiliki akses terhadap layanan jasa keuangan yang berkualitas dengan biaya yang terjangkau dan cara yang menyenangkan, tidak rumit, serta menjunjung harga diri dan kehormatan (Radyati 2012).

Dilihat secara konsepsi, koperasi syariah merupakan suatu lembaga yang eksistensinya sangat dibutuhkan masyarakat terutama kalangan mikro. Akan tetapi di sisi lain, yaitu dalam bidang operasionalnya masih memiliki banyak kelemahan. Maka problematika tersebut harus dapat diatasi dengan baik agar 
mampu mewujudkan terciptanya citra positif bagi lembaga keuangan mikro syariah yang bersih serta dipercaya oleh masyarakat.

Oleh karena itu, berdasarkan latar belakang yang telah diungkapkan di atas, maka tulisan ini bermaksud mengkaji apa saja hambatan yang dihadapi oleh institusi lembaga keuangan mikro syariah di Indonesia, dan apa saja kebutuhan, tujuan dan ukuran keberhasilan serta ukuran efektifitas pengembangan koperasi syariah di Indonesia. Dengan pendekatan metode Interpretative Structural Modelling (ISM) beberapa pertanyaan tersebut akan coba dijawab dan dicarikan solusinya.

Siswanto (Siswanto 2009) dalam penelitiannya yang berjudul "Strategi Pengembangan Baitul Maal Wattamwil (BMT) dalam Memberdayakan Usaha Kecil dan Menengah" berupaya untuk mengidentifikasi dan menganalisis model BMT yang dapat memberdayakan usaha kecil, serta dapat menemukan strategi dan upaya agar BMT mampu memberdayakan Usaha Kecil Menengah. Penelitian ini dilakukan menggunakan metode deskriptif dengan teknik analisis analisa isi tema dari data literatur dan penelitian sebelumnya terkait penelitiannya. Penelitian ini mencoba menganalisa kelemahan dan pengembangan kelebihan dari lembaga BMT dengan menggunakan teknik SWOT, kemudian dilanjutkan dengan mengemukakan solusi dan strategi dalam pengembangan BMT. Di antara kelemahan BMT adalah terdiri dari: (a) faktor eksternal (tingkat kompetisi dengan pesaing, koloborasi atau kerja sama dengan lembaga keuangan, kebijakan pemerintah serta faktor eksternal yang lain seperti LSM), (b) faktor internal (produk program pembiayaan dan tabungan, kompetensi manajemen serta pengelolaan keuangan). Solusi yang ditawarkan terkait dengan permasalahan tersebut adalah perlunya memfokuskan diri pada visi dan penciptaan image yang positif bagi masyarakat, prospek bisnis, kapasitas manajemen, sistem teknologi, operasional dan resiko.

Penelitian lain terkait strategi pengembangan lembaga keuangan mikro syariah (LKMS) dilakukan Rusydiana dan Devi (Rusydiana and Devi 2013a). 
Penelitian ini mencoba untuk mengidentifikasi penyebab serta faktor-faktor yang dominan menjadi hambatan dalam pengembangan LKMS di Indonesia, dengan pendekatan metode BOCR Analytic Network Process (ANP), termasuk solusi strategis yang diusulkan. Berdasarkan urutan prioritas, maka alternatif aspek menunjukkan bahwa aspek technical menjadi aspek prioritas, selanjutnya diikuti oleh aspek legal/struktur, pasar/komunal, dan SDM. Penguraian solusi secara keseluruhan menghasilkan urutan prioritas: (1) Pembinaan/ sosialisasi/ pendampingan masyarakat menjadi prioritas utama, selanjutnya diikuti oleh (2) inovasi produk, (3) lokasi strategis, (4) kerjasama dengan LKS lainnya, dan (5) menjadikan elemen eksternal sebagai pusat informasi dan media sosialisasi. Sedangkan prioritas strategi yang dianggap dapat meningkatkan pengembangan LKMS di Indonesia terdiri dari: (1) mengoptimalkan peran pemerintah dalam pendanaan, (2) melakukan koordinasi dengan PINBUK, dan (3) linkage program LKMS-BMT-BPRS-Bank Umum Syariah.

Di tempat lain, Muhar (Muhar 2009) menganalisis peran lembaga keuangan mikro bagi masyarakat kecil serta strategi yang dilakukan dalam pengembangan LKM. Hasil penelitian menunjukkan bahwa lembaga keuangan mikro mampu memberikan pembiayaan kepada usaha mikro, sehingga dapat meningkatkan permodalan usaha mikro tersebut. Namun, potensi ini belum dapat dimanfaatkan dengan optimal karena masih terdapat kendala-kendala yang dihadapi oleh lembaga keuangan mikro, antara lain aspek kelembagaan yang tumpang tindih, kekurangan sumber daya dalam pengelolaan LKM serta kurangnya permodalan LKM sendiri. Dalam tulisan ini peneliti memberikan solusi dengan upaya menguatkan RUU tentang kelembagaan LKM. serta komitmen pemerintah terhadap keterkaitan UKM dengan pengembangan lembaga keuangan mikro.

Tidak kalah penting adalah hasil penelitian yang dilakukan oleh Othman et al. (Othman, Kari, and Hamdan 2013) dan Smolo (Smolo 2007). Othman et al. (Othman, Kari, and Hamdan 2013) mencoba melihat komparasi antara 
koperasi syariah dengan perbankan konvensional di Malaysia. Sementara itu, Smolo (Smolo 2007) lebih fokus pada konsep 'kredit mikro' dalam perspektif Islam dan perbedaannya dengan konsep ribawi.

\section{Metode Penelitian}

\section{Sumber dan Metode Pengumpulan Data}

Data yang digunakan dalam penelitian ini merupakan data primer yang diperoleh dari hasil wawancara dengan pakar dan praktisi yang berjumlah 9 (sembilan) orang, kuisioner yang disebarkan kepada responden yang ada di dalamnya, dan studi literatur yang berhubungan dengan masalah-masalah yang dihadapi dalam pengembangan koperasi syariah di Indonesia untuk meningkatkan UMKM.

Beberapa subelemen strategi pengembangan koperasi syariah di Indonesia untuk meningkatkan UMKM diperoleh dari studi pustaka dan diskusi. Strategi-strategi tersebut akan dituangkan dalam bentuk kuisioner dengan menggunakan pendekatan Interpretative Structural Modelling (ISM), mengikuti Saxena dengan sembilan elemen yakni: kebutuhan, kendala atau permasalahan, perubahan yang dimungkinkan, tujuan, tolok ukur keberhasilan, kegiatan/aktivitas, pelaku, segmen masyarakat yang terpengaruh, dan ukuran efektivitas.

\section{Gambaran Umum Metode Interpretative Structural Modelling}

Interpretative Structural Modelling (ISM) merupakan teknik pemodelan yang dikembangkan untuk perencanaan kebijakan strategi (Marimin 2004). ISM diciptakan pertama kali oleh J. Warfield pada tahun 1973, dimana Warfield mendefinisikan ISM sebagai proses belajar dengan bantuan komputer yang memungkinkan individu-individu atau kelompok untuk mengembangkan peta hubungan yang kompleks antara berbagai elemen yang terlibat dalam situasi yang kompleks. 
Mengembangkan Koperasi Syariah di Indonesia...

Interpretive Structural Modelling (ISM) sebagaimana diaplikasikan oleh Bhattacharya dan Momaya (Bhattacharya and Momaya 2009), adalah metodologi perencanaan interaktif canggih yang memungkinkan sekelompok orang, bekerja sebagai tim, untuk mengembangkan struktur yang mendefinisikan hubungan di antara unsur-unsur dalam suatu himpunan. Struktur diperoleh dengan menjawab pertanyaan sederhana. Unsur yang akan terstruktur (seperti tujuan, hambatan, masalah, dan sebagainya) yang ditentukan oleh kelompok pada awal sesi perencanaan ISM. Proses ISM dimulai dari permodelan sistem dan diakhiri dengan validasi model. Melalui teknik ISM, model mental yang tidak jelas ditransformasikan menjadi model sistem yang tampak (visible).

ISM merupakan metode dalam pengambilan keputusan dari situasi yang kompleks dengan menghubungkan dan mengorganisasi ide dalam peta map visual. Dalam hal pengambilan keputusan, ISM ada sedikit kesamaan dengan metode Analytic Network Process (ANP) yang dikembangkan Thomas L. Saaty, seperti penelitian yang dilakukan oleh Rusydiana \& Devi (Rusydiana and Devi 2013b). Ide dasarnya adalah menggunakan ahli yang berpengalaman dan pengetahuan praktis untuk menguraikan sistem yang rumit menjadi beberapa sub-sistem (elemen) dan membangun sebuah model struktural bertingkat. ISM sering digunakan untuk memberikan pemahaman dasar situasi yang kompleks, serta menyusun tindakan untuk memecahkan masalah (Gorvett and Liu 2007).

Dalam pelaksanaan metode ISM terlebih dahulu dilakukan diskusi dengan para pakar (brainstorming) untuk menjaring ide-ide pengembangan organisasi yang terdiri dari orang-orang yang memahami konsep ISM, mengerti masalah pengembangan model pengembangan koperasi syariah, memiliki keahlian di bidang microfinance dan empowerment. Dari diskusi mengenai strategi pengembangan tersebut diperoleh beberapa ide atau variabel yang akan diolah menggunakan ISM.

Economica: Jurnal Ekonomi Islam - Volume 9, Nomor 1 (2018)

http://journal.walisongo.ac.id/index.php/economica 
Langkah pertama dalam pengolahan ISM adalah membuat Structural Self Interaction Matrix (SSIM), di mana variabel-variabel tersebut dibuat hubungan konstektualnya dengan menjadikan satu variabel $i$ dan variabel $j$. Selanjutnya adalah membuat Reachibility Matrix (RM) dengan mengubah V, A, $\mathrm{X}$ dan $\mathrm{O}$ dengan bilangan 1 dan 0 . Langkah terakhir adalah membuat Canonical Matrix untuk menentukan level melalui iterasi. Setelah tidak ada lagi irisan (intersection), selanjutnya dibuat model yang dihasilkan oleh ISM yang merupakan suatu model untuk memecahkan masalah, dalam hal ini pengembangan model koperasi syariah. Dari model tersebut kemudian nantinya akan dibuat suatu road map pengembangan lembaga (level).

Ada beberapa penelitian yang telah dilakukan dengan menggunakan metode ISM. Beberapa di antaranya adalah yang dilakukan oleh Ascarya et al. (2012) terkait pengembangan bank syariah, Devi dan Rusydiana (Devi and Rusydiana 2016) tentang pinjaman berbasis kelompok, Bolaños et al. (Bolaños et al. 2005), dan Kanungo \& Bhatnagar (Kanungo and Bhatnagar 2002) untuk aplikasi industri lain. Sementara itu penelitian dengan metode ISM yang sifatnya lebih teoretis telah dilakukan oleh Lee (Lee 2007) dan Thakkar et al. (Thakkar et al. 2006).

\section{Hubungan antarelemen dalam ISM}

Menurut Marimin (Marimin 2004) proses metode ISM adalah dilakukan perhitungan menurut Aturan Transivity di mana dilakukan koreksi terhadap SSIM sampai terjadi matriks yang tertutup. Modifikasi SSIM membutuhkan masukan dari para panelis/pakar, dengan diberi catatan khusus agar perhatian ditunjukan hanya pada subelemen tertentu. Hasil revisi SSIM dan matriks yang memenuhi syarat Aturan Transivity diproses lebih lanjut. Untuk revisi dapat juga dilakukan transformasi matriks dengan program komputer.

Aturan Transivity merupakan aturan kelengkapan dari lingkaran sebab akibat (casual-loop), sebagai misal: 
A memengaruhi $\mathrm{B}$

B memengaruhi $\mathrm{C}$

Maka A (seharusnya) memengaruhi C

D meningkatkan E

E meningkatkan $\mathrm{F}$

Maka D (tidak seharusnya) memperkecil F

Tabel 1. Keterkaitan antar Subelemen pada Teknik ISM

\begin{tabular}{|c|c|c|}
\hline No. & Jenis & Interpretasi \\
\hline 1 & Pembandingan (Coperative) & - A lebih penting/besar/indah, daripada B \\
\hline 2 & Peryataan (Definitive) & $\begin{array}{l}\text { - A adalah atribut B } \\
\text { - A termasuk didalam B } \\
\text { - A mengartikan B }\end{array}$ \\
\hline 3 & Pengaruh (Influence) & $\begin{array}{l}\text { - A menyebabkan B } \\
\text { - A adalah debagia penyebab B } \\
\text { - A mengembangkan B } \\
\text { - A menggerakkan B } \\
\text { - A meningkatkan B }\end{array}$ \\
\hline 4 & Ruang (Spiral) & $\begin{array}{l}\text { - A adalah selatan/ utara B } \\
\text { - A di atas B } \\
\text { - A di sebelah kiri B }\end{array}$ \\
\hline 5 & Waktu (Temporate/Time Scale) & $\begin{array}{l}\text { - A mendahului B } \\
\text { - A mengikuti B } \\
\text { - A mempunyai prioritas lebih dari B }\end{array}$ \\
\hline
\end{tabular}

Pengolahan lebih lanjut dari Reachability Matrixyang telah memenuhi Aturan Transivity adalah penetapan pilihan jenjang (level partition). Pengolahan bersifat tabulatif dengan pengisisan format, dan bisa dibantu dengan komputer. Berdasarkan pilihan jenjang maka dapatlah digambarkan skema setiap elemen menurut jenjang vertikal maupun horisontal.

Economica: Jurnal Ekonomi Islam - Volume 9, Nomor 1 (2018) http://journal.walisongo.ac.id/index.php/economica 


\section{Proses Teknik Interpretative Structural Modelling}

Untuk beragam subelemen dalam suatu elemen berdasar RM disusunlah Driver-Power-Dependence. Klasifikasi subelemen dipaparkan dalam 4 sektor berikut (Marimin, 2004):

Sektor 1: Weak driver-weak dependent variables (AUTONOMOUS). Perubahan di sektor ini umumnya tidak berkaitan dengan sistem, dan mungkin memiliki hubungan kecil, meskipun hubungan bisa saja kuat.

Sektor 2: Weak driver-strongly dependent variables (DEPENDENT). Umumnya perubahan di sini tidak bebas.

Sektor 3: Strong driver-strongly dependent variables (LINKAGE). Peubah pada sektor ini harus dikaji secara hati-hati sebab hubungan antarpeubah adalah tidak stabil. Setiap tindakan pada peubah tersebut akan memberikan dampak terhadap lainnya dan umpan balik pengaruhnya bisa memperbesar dampak.

Sektor 4: Strong drive weak dependent variables (INDEPENDENT). Peubah pada sektor ini merupakan bagian sisa dari sistem dan disebut peubah bebas.

Dalam keseluruhan proses teknik ISM maka berbagai urutan kerja dari tahap penyusunan hierarki sampai hasil analisis dapat dilihat pada gambar di bawah. Tergantung kepada kehendak dan tim perekayasa model serta persyaratan dari perihal yang dikaji, berbagai macam bentuk struktur model dapat dibangkitkan dalam ISM. Berdasarkan pengalaman empirik dalam menyusun subelemen dari suatu elemen tertentu, awalnya diperlukan daftar selengkap mungkin (exhausted list). Setelah itu dilakukan pengurangan dengan prinsip eliminasi subelemen yang tidak begitu penting; dan atau menyatukan dua atau tiga sub-elemen. 
Mengembangkan Koperasi Syariah di Indonesia...

\section{Hasil dan Pembahasan}

\section{Elemen Kebutuhan}

Elemen kebutuhan dalam strategi pengembangan koperasi syariah di Indonesia untuk meningkatkan UMKM dijabarkan dalam 9 (sembilan) subelemen sebagai berikut: (E1) meningkatkan manajemen akuntansi dengan menggunakan IT, (E2) dukungan yang kuat untuk hukum koperasi syariah, (E3) SDM koperasi syariah yang profesional, (E4) meningkatkan kesejahteraan (standard of living), (E5) meningkatkan kesempatan pekerjaan untuk masyarakat kurang mampu, (E6) mengadakan sistem pembiayaan yang cocok untuk unbanked moslem people's needs, (E7) menyediakan kesesuaian syariah lembaga keuangan dan ketersediaan DPS (Dewan Pengawas Syariah) pada koperasi syariah, (E8) efisiensi biaya operasional, (E9) meningkatkan sosialisasi dan promosi koperasi syariah.

Hasil dari pengolahan ISM untuk elemen kebutuhan dapat dilihat dibawah ini, dengan rincian sebagai berikut:

Gambar 1. Model Struktur Elemen Kebutuhan

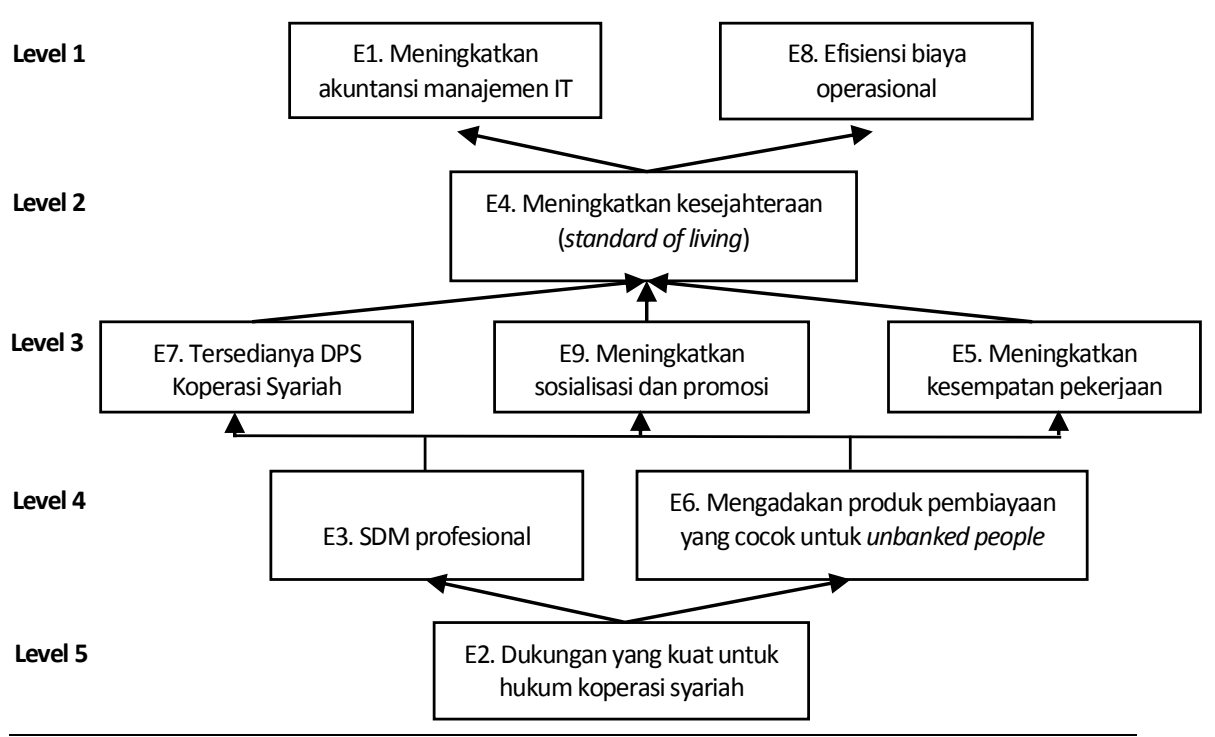

Economica: Jurnal Ekonomi Islam - Volume 9, Nomor 1 (2018)

http://journal.walisongo.ac.id/index.php/economica 
Gambar 1. menunjukkan urutan tahap kebutuhan dalam penerapan strategi pengembangan koperasi syariah di Indonesia untuk meningkatkan UMKM. Level paling terakhir yakni level 5 merupakan subelemen kunci dari elemen kebutuhan, artinya dukungan yang kuat untuk hukum koperasi syariah baik dari aspek hukum syariah maupun hukum positif memiliki pengaruh paling besar dalam menerapkan strategi pengembangan Koperasi Syariah di Indonesia. Maka diharapkan jika adanya dukungan yang kuat untuk hukum koperasi syariah menjadi lebih optimal maka dapat men-generate variabel pada level yang di atas yaitu dapat menciptakan SDM yang profesional dan bekerja sesuai dengan prinsip-prinsip syariah pada lembaga keuangan non-bank, serta produk pembiayaan yang sesuai dengan syariah baik dari aspek akad maupun penerapan pembiayaan. Melalui level 4 ini maka keberadaan DPS pada koperasi syariah akan menjadi sangat penting dan dapat diwujudukan. Sosialisasi dan promosi harus lebih gencar untuk mendapatkan nasabah (anggota koperasi), hingga akhirnya dapat meningkatkan kesempatan pekerjaan. Melalui level ini diharapkan dapat meningkatkan standar hidup masyarakat, dan akhirnya peningkatan akuntansi manajemen IT dapat diwujudkan serta efisiensi biaya operasional pun tercapai.

\section{Elemen Perubahan yang Dimungkinkan}

Elemen perubahan yang dimungkinkan dalam strategi pengembangan koperasi syariah di Indonesia untuk meningkatkan UMKM dijabarkan dalam 9 (sembilan) subelemen sebagai berikut: (E1) tersedianya manajemen akuntansi dengan menggunakan IT, (E2) standarisasi hukum koperasi syariah, (E3) tersedianya SDM koperasi syariah yang profesional, (E4) mempercepat peningkatan kesejahteraan masyarakat di Indonesia, (E5) mempercepat peningkatan kesempatan pekerjaan, (E6) unbanked people dapat berubah menjadi bankable people, (E7) tersedianya DPS (Dewan 
Pengawas Syariah) pada koperasi syariah, (E8) tercapainya efisiensi biaya operasional, (E9) mempercepat sosialisasi dan promosi koperasi syariah.

Hasil dari pengolahan ISM untuk elemen perubahan yang dimungkinkan dapat dilihat dalam Gambar 2, dengan rincian sebagai berikut:

Gambar 2. Model Struktur Elemen Perubahan yang dimungkinkan

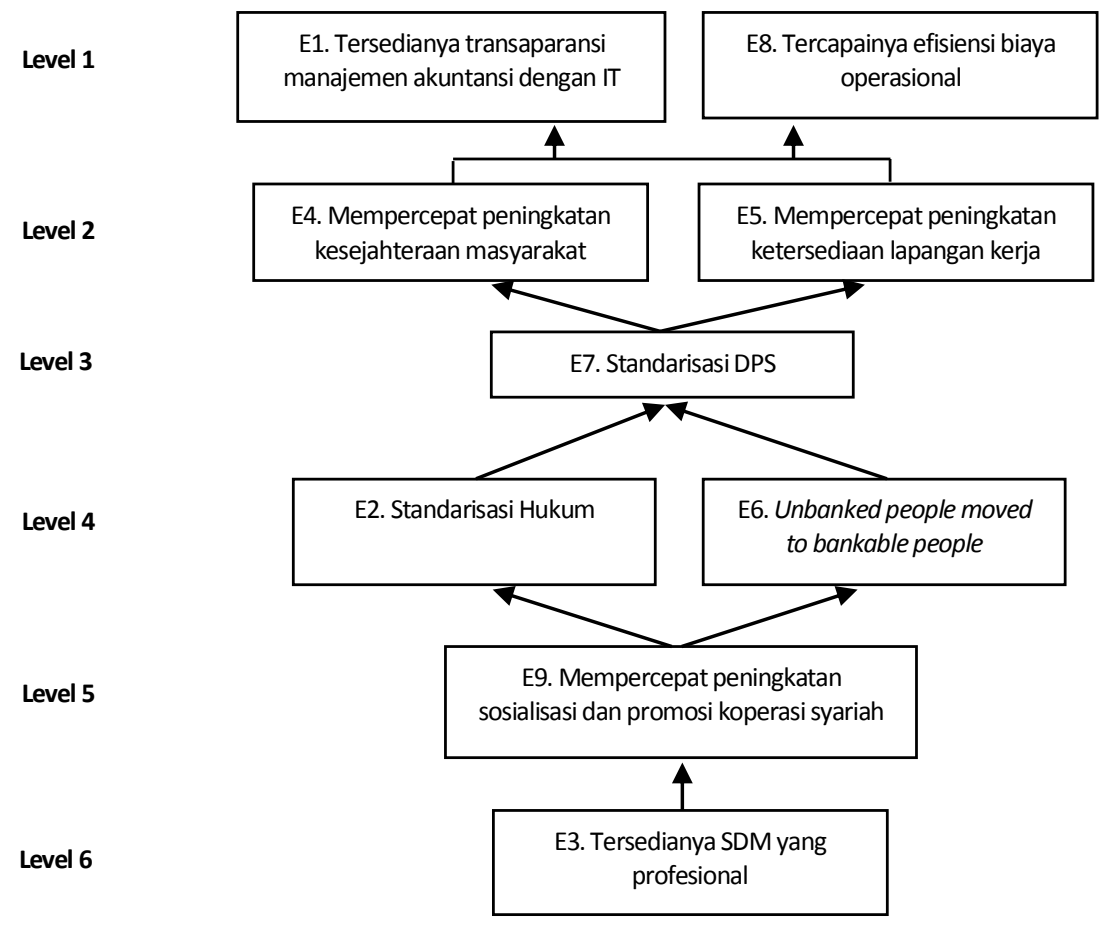

Hasil pengolahan ISM menunjukkan urutan tahap perubahan yang dimungkinkan dalam penerapan strategi pengembangan koperasi syariah di Indonesia untuk meningkatkan UMKM. Level paling terakhir yakni level 6 merupakan subelemen kunci dari elemen perubahan yang dimungkinkan, yaitu tersedianya SDM yang profesional. Senada dengan elemen struktur pada sub bab sebelumnya, bahwa SDM masih menjadi kunci utama yang paling berpengaruh terhadap strategi pengembangan Koperasi Syariah di Indonesia.

Economica: Jurnal Ekonomi Islam - Volume 9, Nomor 1 (2018) 
Diakui bahwa SDM koperasi syariah saat ini memang kebanyakan adalah anggota koperasi itu sendiri, yang secara pendidikan dan kapabilitas manajemen masih terdapat beberapa kelemahan. Namun pada hakikatnya permasalahan lemahnya kualitas SDM koperasi syariah dapat diatasi dengan diadakannya pelatihan kepemimpinan dan kemampuan manajemen koperasi syariah secara kesinambungan, sehingga SDM profesional pun dapat tercapai.

\section{Elemen Tujuan}

Elemen tujuan yang dimungkinkan dalam strategi pengembangan koperasi syariah di Indonesia untuk meningkatkan UMKM dijabarkan dalam 9 (sembilan) subelemen sebagai berikut: (E1) tercapainya transparansi manajemen akuntansi berbasis IT, (E2) memiliki standarisasi hukum koperasi syariah, (E3) memiliki SDM koperasi syariah yang profesional, (E4) tercapainya kesejahteraan masyarakat di Indonesia, (E5) tercapainya peningkatan kesempatan pekerjaan, (E6) tercapainya bankable people, (E7) memiliki DPS (Dewan Pengawas Syariah) pada koperasi syariah, (E8) tercapainya efisiensi biaya operasional, (E9) adanya sosialisasi dan promosi koperasi syariah secara berkesinambungan.

Hasil dari pengolahan ISM untuk elemen tujuan yang dimungkinkan dapat dilihat dalam Gambar 3, dengan rincian sebagai berikut: 
Gambar 3. Model Struktur Elemen Tujuan

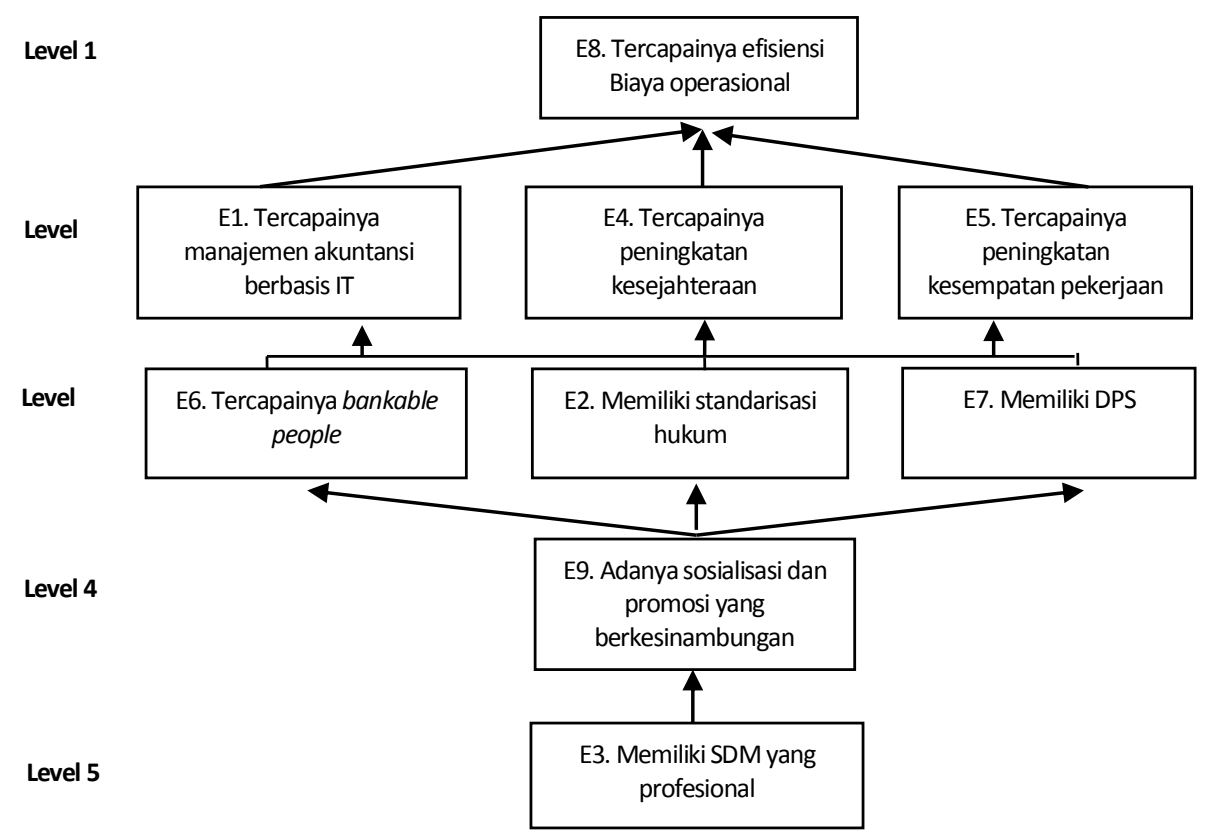

Hasil pengolahan ISM menunjukkan urutan tahap tujuan yang dimungkinkan dalam penerapan strategi pengembangan koperasi syariah di Indonesia untuk meningkatkan UMKM. Level paling terakhir yakni level 5 merupakan subelemen kunci dari elemen tujuan yang dimungkinkan, yaitu memiliki SDM yang profesional. Senada dengan elemen struktur pada sub bab sebelumnya, bahwa SDM masih menjadi kunci utama yang paling berpengaruh terhadap strategi pengembangan koperasi syariah di Indonesia. Tujuan utama dari pengembangan koperasi syariah di Indonesia harus diawali dengan kepemilikan SDM yang profesional. SDM yang profesional dapat menjadi aset penting bagi koperasi syariah agar dapat bersaing dengan lembaga keuangan non-bank yang bersifat mikro lainnya dan terlebih lagi adalah dapat bersaing dengan para rentenir-rentenir yang masih menjadi alternatif pembiayaan lainnya bagi UMKM.

Economica: Jurnal Ekonomi Islam - Volume 9, Nomor 1 (2018) 


\section{Elemen Kegiatan atau Aktivitas}

Elemen kegiatan atau aktivitas dalam strategi pengembangan koperasi syariah di Indonesia untuk meningkatkan UMKM dijabarkan dalam 9 (sembilan) subelemen sebagai berikut: (E1) design dan develop manajemen akuntansi berbasis IT, (E2) design dan develop standarisasi hukum syariah dan hukum positif koperasi syariah, (E3) mengadakan training dan program sertifikasi untuk SDM, (E4) design dan develop program-program pembiayaan untuk meningkatkan UMKM, (E5) menciptakan lapangan pekerjaan untuk masyarakat melalui usaha mikro, (E6) mengadakan pendidikan, pelatihan, dan evaluasi rutin tentang program bisnis bagi unbankable people, (E7) penempatan DPS dalam manajemen organisasi koperasi syariah, (E8) mengurangi biaya operasional melalui penerapan IT, (E9) meningkatkan kerjasama dengan Pemda, akademisi (universitas), dan komunitas lainnya. Hasil dari pengolahan ISM untuk elemen kegiatan atau aktifitas yang dimungkinkan dapat dilihat dalam Gambar 4, dengan rincian sebagai berikut:

Gambar 4. Model Struktur Elemen Kegiatan atau Aktivitas

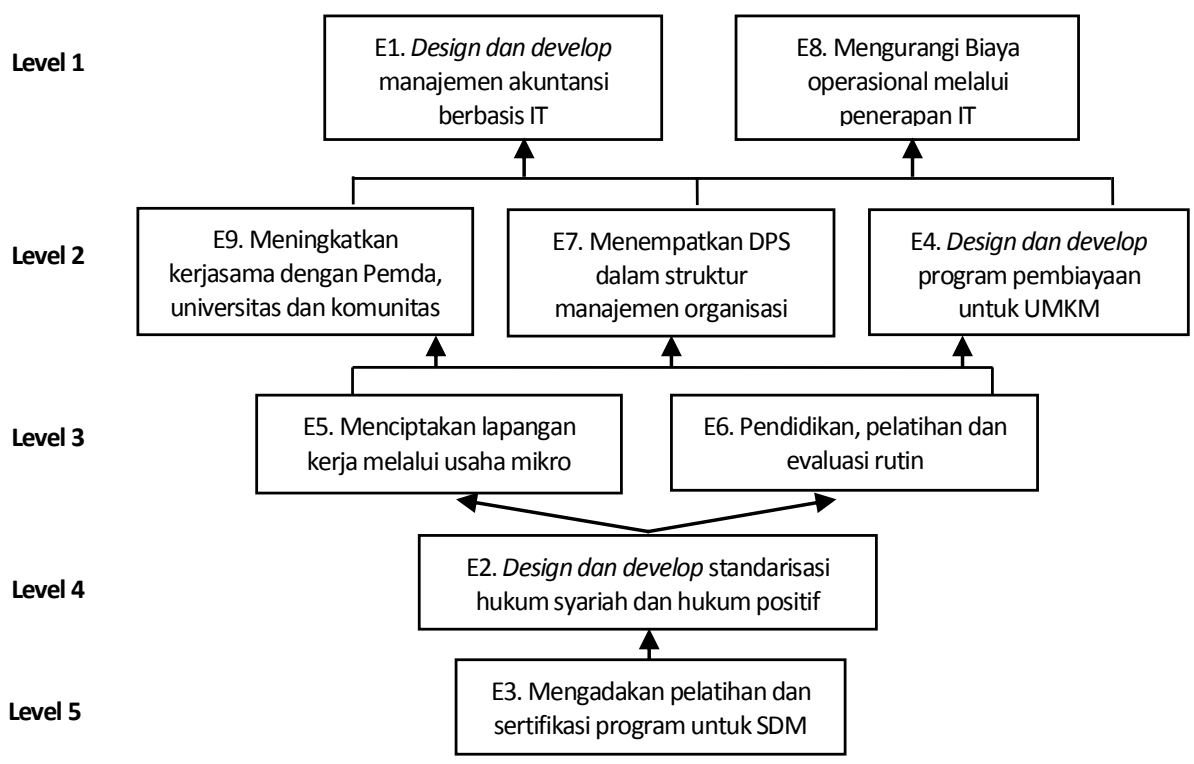


Hasil pengolahan ISM menunjukkan urutan tahap elemen kegiatan atau aktivitas yang dimungkinkan dalam penerapan strategi pengembangan koperasi syariah di Indonesia untuk meningkatkan UMKM. Level paling terakhir yakni level 5 merupakan subelemen kunci dari elemen kegiatan, yaitu mengadakan pelatihan dan sertifikasi program untuk SDM. Senada dengan elemen struktur pada sub bab sebelumnya, bahwa SDM masih menjadi kunci utama yang paling berpengaruh terhadap strategi pengembangan koperasi syariah di Indonesia. Maka dapat disimpulkan bahwa aktivitas prioritas yang perlu dilakukan agar dapat mengembangkan koperasi syariah di Indonesia adalah dengan mengadakan pelatihan dan sertifikasi program untuk SDM manajemen koperasi. Namun demikian, pelatihan juga dapat dilakukan kepada seluruh anggota koperasi syariah. Pelatihan yang diadakan dapat berupa pelatihan manajemen kepemimpinan, manajemen keuangan koperasi syariah, penerapan akad-akad syariah, kewirausahaan dan sebagainya yang dibutuhkan oleh koperasi syariah.

\section{Elemen Pelaku atau Lembaga}

Elemen pelaku atau lembaga dalam strategi pengembangan koperasi syariah di Indonesia untuk meningkatkan UMKM dijabarkan dalam 7 (tujuh) subelemen sebagai berikut: (E1) Kementerian Koperasi dan UMKM, (E2) Pemerintah Daerah, (E3) Lembaga Keuangan Syariah (termasuk dalam hal ini Lembaga perbankan, non-perbankan, dan koperasi syariah), (E4) UMKM, (E5) komunitas, (E6) DSN-MUI (sharia advisor), (E7) Akademisi.

Hasil dari pengolahan ISM untuk elemen pelaku atau lembaga dapat dilihat dalam Gambar 5, dengan rincian sebagai berikut: 


\section{Gambar 5. Model Struktur Elemen Pelaku/lembaga}

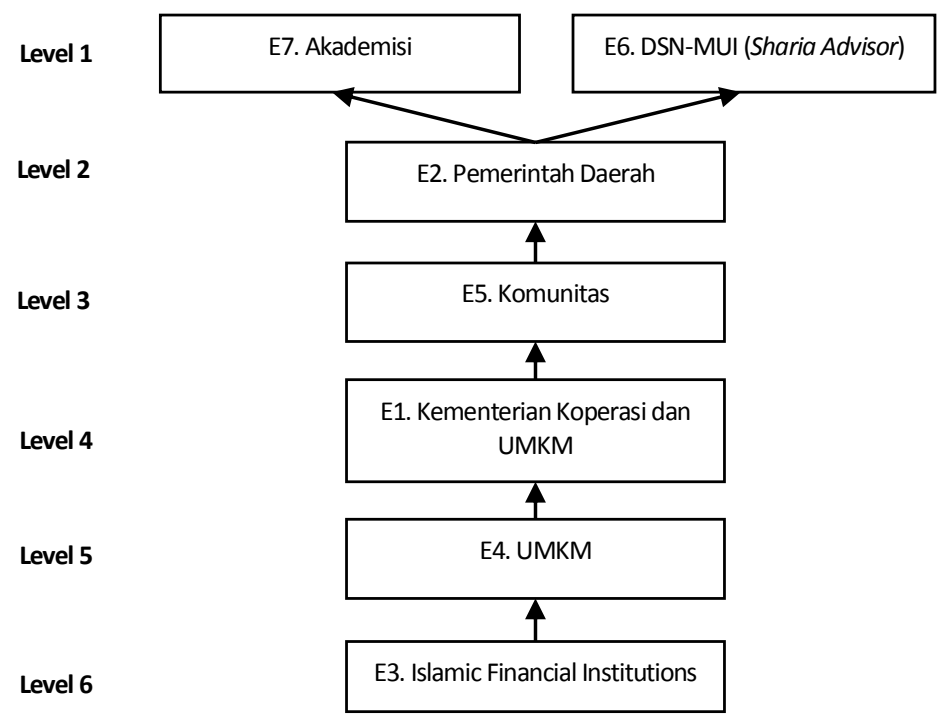

Lembaga keuangan syariah berperan penting dalam strategi pengembangan Koperasi Syariah di Indonesia untuk meningkatkan UMKM. Lembaga keuangan syariah menjadi elemen kunci dalam mengembangkan koperasi syariah di Indonesia untuk meningkatkan UMKM. Hal ini berarti bahwa perlu ada komitmen dan keseriusan dari lembaga keuangan syariah untuk saling berkoordinasi dan bekerja sama dalam memberikan pembiayaan khususnya bagi masyarakat yang unbankable. Salah satu kelemahan masyarakat yang unbankable adalah sulitnya akses terhadap lembaga keuangan untuk memperoleh permodalan karena terkendala tidak adanya agunan. Maka, tidak sedikit masyarakat yang unbankable terjerat hutang kepada rentenir yang lebih mudah diakses dan tidak membutuhkan agunan. Namun tentunya ini menjadi polemik tersendiri sehingga lembaga keuangan syariah harus mendapatkan peluang untuk menjadikan masyarakatmasyarakat unbankable sebagai segmen pasar khususnya bagi koperasi syariah. 
Mengembangkan Koperasi Syariah di Indonesia...

\section{Subelemen Kunci Strategi Pengembangan Koperasi Syariah}

Subelemen kunci utama merupakan subelemen yang dijadikan sebagai motor penggerak, yang dalam implementasinya dapat menjadi subelemen utama yang perlu diperhatikan. Karena subelemen kunci ini dapat memengaruhi sukses atau tidaknya subelemen lain. Dalam penelitian ini peneliti mengumpulkan persepsi dari pakar dan praktisi mengenai subelemen kunci yang telah disepakati. Subelemen kunci utama dalam penelitian ini adalah perlu adanya dukungan hukum dalam bentuk standarisasi hukum koperasi syariah, baik itu dalam bentuk hukum syariah maupun hukum positif. Selain itu, diperlukan adanya SDM manajemen koperasi syariah yang berkualitas dan profesional. Strategi ini untuk menjawab kelemahan dan hambatan yang dihadapi oleh koperasi syariah selama ini adalah kurangnya dukungan hukum serta kurangnya SDM koperasi syariah yang profesional.

Selanjutnya subelemen kunci dari perubahan yang dimungkinkan yakni menyiapkan SDM koperasi syariah yang profesional. Untuk mewujudkan SDM yang profesional maka dapat diadakan pelatihan dan pendidikan untuk meningkatkan pengetahuan/keahlian karyawan koperasi syariah, pengembangan variasi produk koperasi syariah, serta memberikan sertifikasi bagi SDM yang profesional. Menurut prioritas, maka lembaga keuangan syariah memiliki peran penting dalam meningkatkan peran koperasi syariah untuk membiaya UMKM, diikuti oleh UMKM itu sendiri, Kementerian Koperasi dan UMKM, komunitas, Pemda, DSN-MUI dan terakhir adalah akademisi. Elemen segmen masyarakat yang paling berdampak dari strategi pengembangan koperasi syariah ini adalah pelaku UMKM dan diikuti oleh komunitas-komunitas usaha.

Economica: Jurnal Ekonomi Islam - Volume 9, Nomor 1 (2018) http://journal.walisongo.ac.id/index.php/economica 


\section{Simpulan}

Perlu ada strategi pengembangan koperasi syariah di Indonesia agar dapat mengoptimalkan peran koperasi syariah dalam meningkatkan sektor UMKM di Indonesia. Penelitian ini mencoba untuk mengurai subelemen kunci agar strategi pengembangan koperasi syariah dapat berjalan secara optimal. Hasil penelitian ini memberikan beberapa kesimpulan di antaranya:

Pertama, elemen kebutuhan yang menjadi kunci utama dalam strategi pengembangan koperasi syariah di Indonesia untuk meningkatkan UMKM adalah perlu adanya dukungan yang kuat pada aspek hukum koperasi syariah (hukum positif dan hukum syariah). Kedua, elemen perubahan yang dimungkinkan yang menjadi kunci utama dalam strategi pengembangan koperasi syariah di Indonesia untuk meningkatkan UMKM adalah tersedianya SDM koperasi syariah yang profesional. Ketiga, elemen tujuan yang menjadi kunci utama dihadapi dalam strategi pengembangan koperasi syariah di Indonesia untuk meningkatkan UMKM adalah koperasi syariah memiliki SDM yang profesional. Keempat, elemen aktifitas yang menjadi kunci utama dalam strategi pengembangan koperasi syariah di Indonesia untuk meningkatkan UMKM adalah mengadakan training dan program sertifikasi bagi manajemen koperasi syariah dan anggota. Kelima, elemen pelaku/lembaga yang menjadi kunci utama dalam strategi pengembangan koperasi syariah di Indonesia untuk meningkatkan UMKM adalah lembaga keuangan syariah.

Berdasarkan hasil penelitian ini, maka berikut beberapa rekomendasi yang dapat peneliti berikan kepada para stakeholders koperasi syariah di antaranya adalah diperlukan adanya koordinasi dan kerjasama antara seluruh pemangku kebijakan dan pelaku koperasi syariah dalam mewujudkan koperasi syariah yang memilki dukungan hukum yang kuat, profitable, dan menjadi lembaga pembiayaan alternatif bagi masyarakat dengan ekonomi kelas bawah (unbankable people). Sektor UMKM merupakan salah satu sektor usaha yang dominan di Indonesia sehingga perlu didukung melalui aspek permodalan yang kuat. Perbaikan yang berkelanjutan tidak 
Mengembangkan Koperasi Syariah di Indonesia...

hanya dituntut bagi manajemen koperasi akan tetapi juga bagi seluruh anggota koperasi. Anggota koperasi juga membutuhkan pelatihan dan pendidikan untuk menambah skill berbisnis, serta kemampuan dan pemahaman dalam hal penerapan prinsip-prinsip syariah. Jika pelaku UMKM dan komunitas dapat berbisnis secara syariah, maka diharapkan transaksi koperasi syariah dapat menjadi berkah dan profitable.

\section{Daftar Pustaka}

Akanji, 0.0. 2007. "Microfinance as a Strategy for Poverty Reduction.” CBN Economic and Financial Review 39 (4).

Ascarya, Widyo Gunadi, Widodo Cahyono, Enny Anwar, dan Ferry Syarifuddin. 2012. Strategi Meningkatkan Preferensi Perbankan Syariah Indonesia dalam Menggunakan Pembiayaan Bagi Hasil. Jakarta: Central Banking Education and Studies Department, Bank Indonesia

Banerjee, A. V., T. Besley, and T. W. Guinnane. 1994. “Thy Neighbor's Keeper: The Design of a Credit Cooperative with Theory and a Test." The Quarterly Journal of Economics 109 (2). Oxford University Press: 491515. https://doi.org/10.2307/2118471.

Bhattacharya, Sanjay, and K. Momaya. 2009. "Interpretive Structural Modeling of Growth Enablers in Construction Companies." Singapore Management Review 31 (1). Singapore Institute of Management: 73-98. http://go.galegroup.com/ps/anonymous?id=GALE\%7CA192052588 \&sid=googleScholar\&v=2.1\&it=r\&linkaccess=abs\&issn=01295977\&p $=A O N E \& S W=W$.

Bolaños, Ricardo, Emilio Fontela, Alfredo Nenclares, and Pablo Pastor. 2005. "Using Interpretive Structural Modelling in Strategic Decision-making Groups." Management Decision 43 (6). Emerald Group Publishing Limited: 877-95. https://doi.org/10.1108/00251740510603619.

Devi, Abrista, and Aam Rusydiana. 2016. "Islamic Group Lending Model (GLM) and Financial Inclusion." International Journal of Islamic Business Ethics 1 (1): 80-94. https://doi.org/10.30659/IJIBE.1.1.80-94.

Fukuyama, Francis. 2002. "Social Capital and Development: The Coming Agenda.” SAIS Review 22 (1). Johns Hopkins University Press: 23-37. https://doi.org/10.1353/sais.2002.0009.

Economica: Jurnal Ekonomi Islam - Volume 9, Nomor 1 (2018) 
Gorvett, Rick, and Ningwei. Liu. 2007. “Using Interpretive Structural Modeling to Identify and Quantify Interactive Risks." Call Paper Program 2007 ASTIN Colloquium. USA.

Kanungo, Shivraj, and Vivek V. Bhatnagar. 2002. "Beyond Generic Models for Information System Quality: The Use of Interpretive Structural Modeling (ISM)." Systems Research and Behavioral Science 19 (6). WileyBlackwell: 531-49. https://doi.org/10.1002/sres.476.

Lee, D. M. 2007. Structured Decision Making with Interpretive Structural Modelling (ISM). Canada: Sorach Inc.

Lukman, Syukri, Niki Lukviarman, Harif Amali Rivai, Tafdil Husni, Syafrizal, and Maruf. 2008. "Kajian Upaya Penguatan Peran Microbanking Dan Pendekatan Pembiayaan Kelompok Dalam Rangka Pengembangan UMK Di Sumatra Barat." Penelitian atas Kerjasama antara Bank Indonesia dan Center for Banking Research Universitas Andalas.

Marimin. 2004. Pengambilan Keputusan Kreteria Majemuk: Teknik Dan Aplikasi. Jakarta: Gramedia Widiasarana Indonesia.

Muhar. 2009. "Kebijakan Dan Strategi Pengembangan Lembaga Keuangan Mikro." Jurnal Inovasi 6 (4).

Otoritas Jasa Keuangan. 2015. Siaran Pers OJK dan Perbankan Syariah Gelar Expo iB Vaganza 2015. Jakarta.

Othman, Azmah, Fatimah Kari, and Rosita Hamdan. 2013. "A Comparative Analysis of the Co-Operative, Islamic and Conventional Banks in Malaysia." American Journal of Economics 3 (5C): 184-90.

Patten, Richard H, Jay K. Rosengar. 1991. The Development of Rural Banking in Indonesia. San Fransisco: ICS Press.

Radyati, Maria R. Nindita. 2012. Keuangan Inklusif Perbankan. Jakarta: Universitas Trisakti: MMCSR \& MMCE. http://www.mmcrusakti.org.

Robinson, Marguerite S. 2001. The Microfinance Revolution: , Sustainable Finance for the Poor. World Bank. https://openknowledge.worldbank.org/handle/10986/28956.

Rudjito. 2003. "Sinergi Kebijakan dalam Mendorong Pertumbuhan Usaha Mikro Kecil dan Menengah." Paper Dipresentasikan pada Lokakarya Mendorong Pertumbuhan Usaha Kecil dan Menengah yang Sehat dan Berdaya Saing. Asosiasi Pengusaha Indonesia (APINDO), 12 Desemdber. Aston Hotel: Jakarta. 
Mengembangkan Koperasi Syariah di Indonesia...

Rusydiana, Aam Slamet, and Abrista Devi. 2013a. "Challenges in Developing Baitul Maal Wat Tamwiil (BMT) in Indonesia Using Analytic Network Process (ANP)." Business and Management Quarterly Review 4 (2): 5162.

. 2013b. "Mengurai Masalah dan Solusi Pengembangan Lembaga Keuangan Mikro Syariah (LKMS) Di Indonesia: Pendekatan Metode BOCR Analytic Network Process (ANP)." Jurnal Ekonomi Dan Bisnis Islami 3 (1): 19-40.

Saxena, J. P. 1992. "Hierarchy and Classification of Program Plan Element Using Interpretative Structural Modelling." Systems Practice 12 (6): 651-670.

Schurmann, Anna T, and Heidi Bart Johnston. 2009. "The Group-Lending Model and Social Closure: Microcredit, Exclusion, and Health in Bangladesh." Journal of Health, Population, and Nutrition 27 (4). BioMed Central: 518-27. http://www.ncbi.nlm.nih.gov/pubmed/19761085.

Siswanto. 2009. "Strategi Pengembangan Baitull Maal Wattamwil (BMT) dalam Memberdayakan Usaha Kecil dan Menengah." Tesis. Semarang.

Smolo, Edib. 2007. "Microcrediting in Islam: Islamic Micro-Financial Institutions." Paper Dipresentasikan pada International Conference on Islamic Banking and Finance, IIUM Malaysia, April 2007.

Stiglitz, Joseph E. 1990. "Peer Monitoring and Credit Markets." The World Bank Economic Review 4 (3 (September 1990)): 351-66. http://documents.worldbank.org/curated/en/54477146874019642 5/Peer-monitoring-and-credit-markets.

Suharto, Saat. 2010. Outlook BMT 2011. Yogyakarta: Permodalan BMT Center.

Thakkar, Jitesh, S.G. Deshmukh, A.D. Gupta, and Ravi Shankar. 2006. "Development of a Balanced Scorecard: An Integrated Approach of Interpretive Structural Modeling (ISM) and Analytic Network Process (ANP)." International Journal of Productivity and Performance Management 56 (1). Emerald Group Publishing Limited: 25-59. https://doi.org/10.1108/17410400710717073.

Economica: Jurnal Ekonomi Islam - Volume 9, Nomor 1 (2018) 
